\title{
Study of photo-degradation of new 2-oxazoline telluride derivative.
}

\author{
Alfredo R. Marques Oliveira* and Murilo B.Marcondes de Mello \\ Unversidade Federal do Paraná, Departamento de Química, Centro Politécnico, Jd das Américas, Curitiba, \\ 81.531-991 \\ armo@ufpr.br
}

Keywords: photo-degradation, 2-oxazolines, telluride.

\section{INTRODUCTION}

The photooxidation products of di-benzyl-tellurides and arylalkyl tellurides were described by $\mathrm{Cava}^{[1]}$ and Clive $^{2}$. Ferreira ${ }^{3}$ studied the photodegradation process for arylbenzyltellurides. All this results indicates that the processes must be mediated by one or more radicalar steps ${ }^{[2]}$. On the other hand radical tellurides derivatives have considerable potential for use in organic synthesis ${ }^{[4,5]}$.

In this work, is shown the first results of the synthesis of a 2-oxazoline telluride derivative and its photo-degradation behavior.

\section{RESULTS AND DISCUSSION}

2-oxazolinyl-butyl-chacogen (2a-c) were easily prepared by substitution of tosylate (1) with appropriated lithium n-butyl-calcogenolate salt in THF (Scheme 1).

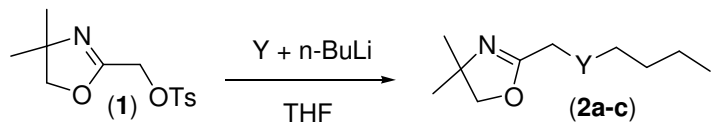

$\mathrm{Y}=\mathrm{S}(\mathbf{2 a}) \mathbf{8 0 \%}, \mathrm{Se}(\mathbf{2 b}) 78 \%$ or Te $(\mathbf{2 c})$ yield not determinded

Figure 1. Synthesis of (2a-c).

However, during the purification process of $(\mathbf{2 c})$ was observed a precipitation of a white solid, as soon as the product leaves the chromatography column. After 30 minutes all purified product was consumed as determined by TLC analysis.

To investigate this process, (2c) was synthesized under white light protection and using deoxygenate helium atmosphere, even through the purification process and characterized by NMR spectrometry and HRMS spectroscopy.

After characterization, compound (2c) was submitted to the photo-degradation conditions using ultra-violet light and an oxygen flow through the solution of $\mathrm{CDCl}_{3}$ or THF. This step was made inside a NMR tube and the tellurium fading was monitored using ${ }^{125} \mathrm{Te}$ NMR experiments as shown in Figure 1.

The telluride (2c) signal at $387 \mathrm{ppm}$ totally disappeared after 40 minutes of degradation using $\mathrm{UV} / \mathrm{O}_{2}$ conditions (Spectrum $\mathrm{C}$ ).

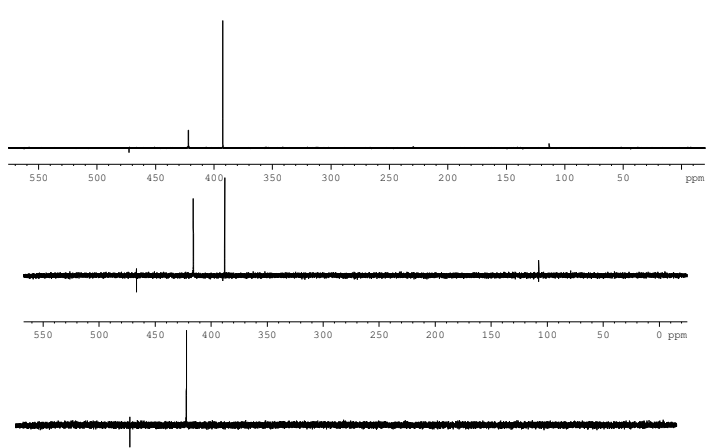

Figure 1. ${ }^{125} \mathrm{Te}$ NMR of degradation of (2c).

The resulting solution was analyzed by GC-FID and 4 out of 7 products were identified (Scheme 2 .

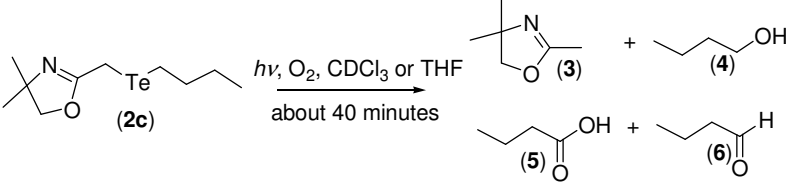

Scheme 2. Photo-degradation of (2c) and the major products.

\section{CONCLUSION}

In this work, we described the first study of photodegradation of alkyloxazolinyl tellurides and the preliminary results of this transformation.

\section{ACKNOWLEDGEMENTS}

CAPES, CNPQ, UFPR and F.Araucária for the financial suport. The authors also thanks to Prof. Dr. J.V. Comasseto, Alcindo dos Santos and the IQUSP for the HRMS analysis.

[1] LEE, H., CAVA, M. P., Journal of the Chemical Society, Chemical Communications, 1981, 277-278.

[2] CRICH, D., CHEN, C., HWANG, J. T., YUAN, H. W., PAPADATOS, A., WALTER, R. I., Journal of the American Chemical Society, 1994, 116, p.8937-8951.

J.T.B., Oliveira, A.R.M.,. Comasseto, J.V., Tetrahedron Lett., 1992,33, 915

[3] OBA, M., ENDO, M., NISHIYAMA, K., OUCHI, A., ANDO, W., Chemical Communications 2004, 1672-1673,.

[4] OUCHI, A., HYUGANO, T., LIU, C., Organic Letters, 2009, 11, 4870-4873.

[5] MEYERS, A. I. The Journal of Organic Chemistry, 2005, 70, 6137-6151. 